\title{
PERCEPÇÃO AMBIENTAL DOS MORADORES DE TRÊS LOTEAMENTOS PARTICULARES EM SANTA MARIA (RS) QUANTO A ARBORIZAÇÃO DE VIAS PÚBLICAS.
}

\author{
Italo Filippi Teixeira ${ }^{1}$, Nara Rejane Zamberlan dos Santos ${ }^{2}$, Sheila de Souza Balest ${ }^{3}$
}

(recebido em 06.02.2008 e aceito para publicação em 14.03.2009)

\begin{abstract}
RESUMO
A arborização das vias que compõem três loteamentos na cidade de Santa Maria-RS foi avaliada por meio de levantamento das espécies existentes e por meio de um instrumento aplicado junto aos moradores cujo objetivo foi identificar a percepção dos moradores quanto à vegetação existente nas vias públicas dos respectivos loteamentos. Os resultados demonstraram que a escolha das espécies, plantio e manejo, cabe aos moradores, os quais apontam esta responsabilidade como inerente ao proprietário, isentando o poder público de tal compromisso.
\end{abstract}

Palavras-chave: floresta urbana, públicas de vias, planejamento.

\section{ENVIRONMENTAL PERCEPTION OF THE RESIDENTS OF THREE PRIVATE DIVISIONS INTO LOTS IN SANTA MARIA (RS) AS ARBORIZATION OF PUBLIC ROADS.}

\begin{abstract}
ABSTRATC
The arborization of the roads that compose three divisions into lots in Saint Maria-RS city it was evaluated through the rising of the existent species and through an applied instrument the residents whose objective was to identify the relationship and the compromising of the same ones with the vegetation existent. The results demonstrated close to that the choice of the species, planting and handling, falls to the residents, which point this responsibility as inherent to the proprietor, exempting the public power of such commitment.
\end{abstract}

Key words: urban forest, public roads, planning.

\footnotetext{
1. Engo . Florestal, Dr., Prof. Adjunto II - Universidade Federal do Pampa - Campus São Gabriel - Av. Antonio Trilha 1847 - Bairro Centro - São Gabriel - RS - 97300-000 - phylippi@gmail.com.

2. Eng ${ }^{\circ}$. Agronomo, Dra ${ }^{\text {. }}$ Prof. Adjunto II - Universidade Federal do Pampa - Campus São Gabriel

3. Eng ${ }^{\circ}$. Florestal
} 
Percepção ambiental dos moradores...

\section{INTRODUÇÃO}

Atualmente, o Brasil apresenta $80 \%$ de sua população vivendo nas cidades (IBGE, 2000). Em muitas dessas, a elevada concentração populacional e as atividades industriais ocasionam sérios problemas ambientais, como: impermeabilização do solo e poluições atmosférica, hídrica, sonora e visual, além da redução da cobertura vegetal em todas as suas formas.

Em janeiro de 1999, através da Lei 9785, ocorreram várias alterações de grande impacto para as administrações, com a flexibilização dos parâmetros urbanísticos exigidos no parcelamento do solo urbano (Lei $n^{\circ}$ 6.766/79), dando maior autonomia aos municípios para a execução de sua própria política urbana. Um exemplo disto é que caberá a legislação urbanística municipal estabelecer à área mínima que deverá ser doada em cada gleba para o sistema de circulação, a implantação de equipamentos urbanos (água, esgoto, energia elétrica, coleta de águas pluviais, rede telefônica, etc...) e comunitários (educação, cultura, saúde e lazer), a instalação de espaços livres e áreas verdes de uso público.

A referida lei ainda determina que para garantir o interesse público e social, a legislação municipal deve estabelecer, no mínimo, 35\% da gleba que será parcelada, a qual será reservada para uso social e ambiental. Este percentual de área doada, normalmente, é distribuído da seguinte forma: 15 a 20\% para sistema viário, 10 a 15\% para área verde e 5 a 10\% para área institucional.

Todo o complexo arbóreo de uma cidade, quer seja plantado ou natural, compõe em termos globais a sua área verde. Todavia, costuma-se excluir a arborização ao longo das vias públicas como integrante de sua área verde, por se considerar acessória e ter objetivos distintos, já que as áreas verdes são destinadas, principalmente, à recreação e ao lazer.

Isto se deve também, ao fato de que a legislação de uso e parcelamento do solo obrigar aos loteadores apenas a destinar uma área verde para praças, silenciando-se sobre arborização das ruas. Outros ainda afirmam que a falta de permeabilidade devida às calçadas, descaracteriza esta forma de arborização como área verde. Analisando-se apenas pelas suas finalidades principais observa-se que são distintas, porém, do ponto de vista ambiental, podendo-se concluir que as árvores existentes ao longo das vias públicas não podem ser excluídas do complexo de áreas verdes da cidade, pois apesar de estarem dispostas de forma linear ou paralela, constituemse muitas vezes em uma "massa verde contínua", propiciando, praticamente, os mesmos efeitos das áreas consideradas como verdes das praças e parques, assim como, podem atuar como corredores ecológicos interligando as mesmas. Ademais, normalmente estas árvores estão protegidas pela legislação municipal contra cortes, de forma que, sua localização acaba sendo perene, fortalecendo o entendimento de que compõem efetivamente a "massa verde urbana". Soma-se a isto a finalidade desta arborização de propiciar um equilíbrio ambiental entre as áreas construídas e o ambiente natural alterado. 
A compreensão científica de como as árvores urbanas e os espaços verdes beneficiam as pessoas cresceu muito nos anos recentes para incluir também os aspectos social, ambiental e econômico. Mas apesar dessa crescente evidência científica, existe um descompasso com relação às políticas públicas adotadas em muitas cidades (Wolf, 2006).

O homem está constantemente agindo sobre o meio ambiente a fim de sanar suas necessidades e desejos. As ações sobre o ambiente, natural ou construído, podem afetar a qualidade de vida de varias gerações e os diversos projetos arquitetônicos ou urbanísticos afetam as respostas dos seus usuários e moradores. E não se esta falando de respostas emocionais, que dependem do humor ou predisposição do momento, mas da própria satisfação psicológica com o ambiente (Okamoto, 1996).

A percepção da população quanto aos benefícios trazidos por uma arborização adequada das áreas urbanas tem sido utilizada em alguns bairros ou cidades do Brasil (Oliveira,2005).

A cidade (o ambiente) compreende fatos físicos (os espaços arquitetônicos, os espaços naturais modificados), e fatos comportamentais (o uso que os indivíduos fazem desses espaços, o apego e o afeto que esses indivíduos têm em relação a esses espaços). Há, na cidade, então, um espaço topológico, ao qual se integra um espaço psicológico. O espaço topológico é mensurável e apresenta características que podem ser captadas com objetividade e descritas, morfológica e funcionalmente. E uma operação seletiva e interpretativa, feita por nossa percepção sobre o espaço topológico, define o espaço psicológico (Castello, 2006).

Perceber o ambiente que se está localizado, aprendendo a proteger e cuidar dele da melhor forma possível, ou seja, uma tomada de consciência do ambiente pelo homem é o que Trigueiro (2003) define como sendo percepção ambiental.

Whyte (1978) comenta que os objetivos da investigação da percepção pelas populações que interagem com o ambiente são: aumentar em todos os domínios a compreensão das bases das diferentes percepções do ambiente; auxiliar na preservação das percepções e os sistemas de conhecimento do meio ambiente, que estão em via de desaparecimento rápido; encorajar a participação da comunidade no desenvolvimento e planejamento; contribuir para uma utilização mais racional dos recursos da biosfera; agir enquanto instrumento educativo.

Estudos de percepção do ambiente têm sido realizados considerando a interação do ser humano com a paisagem (Zube et al., 1982), em que o componente humano compreende a experiência passada, o conhecimento, expectativas e contexto sócio-cultural dos indivíduos e dos grupos.

Nos centros urbanos, as ruas formam áreas livres que são parte das paisagens das cidades. E uma paisagem não pode ser somente feita de elementos artificiais, devem se aliar aos elementos naturais e culturais da cidade, formando um conjunto melhorando a qualidade de vida dos seus moradores. A arborização promove uma série de benefícios para a população, como: estabilização e melhoria do microclima; redução da poluição atmosférica e sonora; melhoria 


\section{Percepção ambiental dos moradores...}

estética; melhoria da saúde humana; e benefícios sociais, econômicos e políticos (Laschi et al., 2000).

Independentemente, dos estudos acadêmicos voltados para definir os benefícios da arborização, responder a essa questão significa avaliar conceitos de difícil quantificação e mesmo qualificação. O "bem-estar", a significância história e cultural e os aspectos psicológicos da comunhão do ser humano com a natureza são alguns desses conceitos. Contudo, alguns aspectos da arborização urbana podem ser mensurados, avaliados e monitorados, caracterizando benefícios e, conseqüentemente, objetivos que passam a ser estabelecidos no planejamento (Milano e Dalcin, 2000).

O espaço físico deve ser administrado de forma a permitir que árvores e redes (aéreas ou subterrâneas) cumpram suas funções de forma harmoniosa, o que só é possível quando são respeitadas suas respectivas necessidades de espaços físicos. Temos que lembrar que as árvores se desenvolvem e, ao serem plantadas, exigem planejamento, a fim de se evitar danos futuros.

Em muitas situações, o planejamento urbano deixa de incluir a arborização, como equipamento a ser devidamente planejado, o que permite, muitas vezes, que iniciativas particulares pontuais e desprovidas de conhecimento ocupem o espaço com plantios irregulares de espécies sem compatibilidade com o local. Como conseqüência, perde-se a eficácia da arborização em transmitir conforto físico e psíquico, acarretando infortúnios e transtornos. Esse tipo de procedimento é muito comum nas cidades brasileiras, o que tem causado, muitas vezes, sérios prejuízos (Silva Filho et al., 2002).

Uma cidade jamais construiria uma estrada ou um sistema hidráulico ou elétrico peça por peça, sem um planejamento prévio, um projeto técnico e uma coordenação. O conceito de "infraestrutura verde" indica que a natureza nas cidades deve ser administrada de maneira integrada, do mesmo modo como os sistemas de saneamento, de transporte, de energia, por exemplo, o são - ou deveriam ser (Wolf, 2006).

Isto posto este trabalho teve o objetivo de analisar a percepção ambiental dos moradores de três loteamentos particulares em Santa Maria-RS, sobre o tema arborização de vias públicas.

\section{MATERIAL E MÉTODOS}

O trabalho foi desenvolvido por meio de um censo da vegetação existente e de uma pesquisa de opinião pública cujo tema principal foi arborização de ruas. Esta pesquisa foi aplicada em todas as noventa e três (93) residências que compõem o Parque Residencial Fiori D'Itália, Parque Universitário e Parque Monte Carlo, distribuídas em onze (11) ruas que constituem estes loteamentos no Bairro Camobi, em Santa Maria-RS e que fazem parte da malha viária urbana. Em cada residência foi entrevistado o proprietário e para tanto fez-se uso do instrumento de avaliação com a seguinte seqüência de perguntas: 
** Identifique a espécie

P1 - Qual o nome da árvore em frente a sua residência? ( )acertou ( )não sabe

P2.1 - Quem plantou o exemplar? ( )atual proprietário ( )antigo proprietário ( )prefeitura ( )não sabe

${ }^{\star \star}$ Caso tenha sido a pessoa que está respondendo perguntar:

P2.2 -Porque escolheu está espécie? ( ) )considera ideal para o espaço ( )porque gosta (ou familiar gosta)

( ) )comprou ao acaso ( )por indicação ( )ganhou;

P 3 - Tem informações sobre a espécie, tais como porte, folhas frutos, raízes, etc? ( )sim ( )não

P 4 - O espaço deixado na calçada é suficiente para o desenvolvimento da planta?( )sim ( )não

** Efetuar a medição da área livre com fita métrica considerando largura X comprimento, em metros

P 5 -O exemplar já foi podado? ( ) )sim ( )não Em caso positivo quem praticou a poda?

P 6 - Qual a função que o exemplar cumpre no local?

( ) embelezamento; ( )sombreamento; ( ) fornecimento de frutos; ( ) ela é um problema

P 7 - Você manteria este exemplar em frente a sua casa ou substituiria? ( ) manteria ( )substituiria qual espécie colocaria?

P 8 - Na sua opinião quem deveria ser responsável pelo plantio e manutenção das árvores das calçadas?

( ) proprietário ( ) prefeitura

** Orientação aos entrevistadores.

\section{RESULTADOS}

A Tabela 1 mostra as espécies vegetais identificadas durante o censo realizado nas onze ruas que compõem os três residenciais. Observa-se que a arborização de ruas está formada por quarenta e duas espécies vegetais, sendo vinte e três (23) exóticas e dezenove (19) nativas, constituídos por oito (8) arbustos, uma (1) palmeira e trinta e três (33) árvores.

Em Lageado-RS, segundo Ruschel e Leite (2002), das espécies levantadas, 53,6 \% são exóticas e 46,4\% são nativas, sendo 33,3 \% nativas no Rio Grande do Sul.

A distribuição observada nos três loteamentos é totalmente irregular, sendo que apenas duas (2) espécies, Lagerstroemia indica e Ligustrum lucidum, perfazem $51,52 \%$ do total inventariado.

Loboda et al. (2005) avaliando o verde de acompanhamento viário da região central do município de Guarapuava-PR, obtiveram, dentre os resultados do trabalho desenvolvido, como as espécies mais plantadas o Ligustrum lucidum com 38,27\% do total existente, assim como, Lagerstroemia indica, 27,23\% e Tipuana tipu, 25,17\% como as outras duas espécies com maiores percentuais, totalizando $91,27 \%$ da arborização do município.

Em Lageado-RS, na área central, Ruschel e Leite (2002) desenvolveram um levantamento quali-quantitativo onde foram amostradas 982 árvores em 14 logradouros. Encontraram-se 69 
Percepção ambiental dos moradores...

espécies distribuídas em 28 famílias sendo que a Extremosa (Lagerstroemia indica) é a espécie mais abundante com 220 indivíduos, representando $22,4 \%$ do total, seguida pelo Ligustro (Ligustrum japonicum) com 162 indivíduos (16,4 \% do total) e o Ipê-amarelo (Tabebuia chrysotricha) com 115 árvores (11,7\% do total).

TABELA 1 - Lista das espécies vegetais encontradas nas ruas dos três residenciais.

\begin{tabular}{|c|c|c|c|c|c|}
\hline Nome botânico & Nome comum & Origem* & $\begin{array}{c}\text { Classe } \\
\text { Vegetal** }\end{array}$ & $\begin{array}{c}\text { Freqüência } \\
\text { Absoluta }\end{array}$ & $\begin{array}{c}\text { Freqüência } \\
\text { Relativa }\end{array}$ \\
\hline Lagerstroemia indica Lam. & Extremosa & $E$ & A & 104 & 39,40 \\
\hline Ligustrum lucidum W.T. Aiton & Ligustro & $E$ & A & 32 & 12,12 \\
\hline Tabebuia chrysotricha (Mart. e DC.) Standley & Ipế-amarelo & $\mathrm{N}$ & A & 12 & 4,55 \\
\hline Senna multijuga (Rich) H.S. Irwin e Barneby & Chuva-de-ouro & $\mathrm{N}$ & $A$ & 11 & 4,17 \\
\hline Hibiscus rosa sinensis L. & Hibisco & $E$ & AR & 9 & 3,41 \\
\hline Mangifera indica L. & Mangueira & $E$ & A & 8 & 3,03 \\
\hline Tabebuia heptaphylla (Vell.) Toledo & Ipê-roxo & $\mathrm{N}$ & $A$ & 7 & 2,65 \\
\hline Jacaranda mimosaefolia D. Don & Jacarandá-mimoso & $\mathrm{N}$ & $A$ & 7 & 2,65 \\
\hline Caliandra selloi (Spreng.) J.F.MacBr. & Caliandra & $\mathrm{N}$ & AR & 6 & 2,27 \\
\hline Grevillea robusta A. Cunn & Grevílea & $E$ & A & 6 & 2,27 \\
\hline Callistemon speciosus (Bonpl.) Sweet. & Escova-de-garrafa & $E$ & AR & 5 & 1,89 \\
\hline Ficus benjamina L. & Ficus golden & $E$ & $A$ & 5 & 1,89 \\
\hline Thuja occidentalis L. & Tuia & $E$ & AR & 5 & 1,89 \\
\hline Melia azedarach L. & Cinamomo & $E$ & A & 4 & 1,51 \\
\hline Inga edulis Mart. & Ingá & $\mathrm{N}$ & $A$ & 4 & 1,51 \\
\hline Syzygium cuminii (L) Skeels & Jambolão & $E$ & $A$ & 4 & 1,51 \\
\hline Citrus $x$ limon (L.) Burm.f. & Limoeiro & $E$ & $A$ & 3 & 1,13 \\
\hline Tipuana tipu (Benth.) O.Kuntze & Tipuana & $E$ & $A$ & 3 & 1,13 \\
\hline Cinnamomum camphora (L)JPresl) & Canela & $\mathrm{N}$ & A & 2 & 0,76 \\
\hline Psidium guajava L. & Goiabeira & $E$ & $A$ & 2 & 0,76 \\
\hline Eugenia uniflora L. & Pitangueira & $\mathrm{N}$ & $A$ & 2 & 0,76 \\
\hline Brunfelsia uniflora Benth. & Primavera & $\mathrm{N}$ & AR & 2 & 0,76 \\
\hline Morus nigra L. & Amoreira & $E$ & AR & 2 & 0,76 \\
\hline Schinus molle L. & Aroeira & $\mathrm{N}$ & A & 1 & 0,38 \\
\hline Schefflera morototoni (Aubl.) Maguire et al. & Caixeta & $\mathrm{N}$ & $A$ & 1 & 0,38 \\
\hline Peltophorum dubium (Spreng.) Taub. & Canafístula & $\mathrm{N}$ & A & 1 & 0,38 \\
\hline Cinnamomom zeylanicum (Breyn.)BI.) & Canela & $E$ & A & 1 & 0,38 \\
\hline Cupressus sempervirens L. & Cipreste & $E$ & AR & 1 & 0,38 \\
\hline Nerium oleander L. & Espirradeira & $E$ & AR & 1 & 0,38 \\
\hline Syagrus romanzoffiana (Cham.) Glassm. & Gerivá & $\mathrm{N}$ & $P$ & 1 & 0,38 \\
\hline Patagonula americana $\mathrm{L}$. & Guajuvira & $\mathrm{N}$ & $A$ & 1 & 0,38 \\
\hline Tabebuia alba (Cham.) Sandwith) & Ipê-da-serra & $\mathrm{N}$ & $A$ & 1 & 0,38 \\
\hline Citrus aurantium L. & Laranjeira-azeda & $E$ & A & 1 & 0,38 \\
\hline Magnolia grandiflora L. & Magnólia & $E$ & $A$ & 1 & 0,38 \\
\hline Carica papaya (L.) & Mamoeiro & $E$ & A & 1 & 0,38 \\
\hline Eriobotrya japonica (Thunb.)Lind. & Nespereira & $E$ & $A$ & 1 & 0,38 \\
\hline Bauhinia forficata Link & Pata-de-vaca & $\mathrm{N}$ & $A$ & 1 & 0,38 \\
\hline Caesalpinia ferrea Mart. & Pau-ferro & $\mathrm{N}$ & $A$ & 1 & 0,38 \\
\hline Prunus persica Sieb. et. Zucc. & Pessegueiro & $E$ & $A$ & 1 & 0,38 \\
\hline Caesalpinia peltophoroides Benth. & Sibipiruna & $\mathrm{N}$ & $A$ & 1 & 0,38 \\
\hline E. contortisiliquum (Vell.) Morong & Timbaúva & $\mathrm{N}$ & A & 1 & 0,38 \\
\hline \multirow[t]{2}{*}{ Campsis grandiflora (Thumb.) K.Schum. } & Trombeta-chinesa & $E$ & AR & 1 & 0,38 \\
\hline & TOTAL & & & 264 & 100 \\
\hline
\end{tabular}

* $\mathrm{E}$ - exótica; $\mathrm{N}$ - nativa; ${ }^{* *} \mathrm{~A}$ - árvore; $\mathrm{AR}$ - arbusto; $\mathrm{P}$ - palmeira.

O levantamento da arborização de ruas realizado por Lima e Tomé (1999) no município de Bandeirantes - PR diagnosticou que do total de 3504 indivíduos inventariados e divididos em 34 espécies, apenas três espécies perfaziam mais de $70 \%$ da arborização, sendo elas: Ligustrum lucidum 44\%, Caesalpinia peltophoroides 15,70\% e Magnolia grandiflora 13,01\%.

Quanto a predominância de uma determinada espécie na arborização de um bairro ou município, Grey e Deneke (1978) recomendam que a mesma não constitua mais de 15\% do total 
da arborização de ruas, porém Moll (1987) considera que a freqüência não deverá ultrapassar aos $10 \%$

Santamour Júnior (2002) é enfático ao afirmar que a diversidade de espécies de árvores na paisagem urbana se faz necessária justamente para garantir a máxima proteção contra pragas e doenças. Dessa forma, o autor recomenda não exceder mais que 10\% da mesma espécie, 20\% de algum gênero e $30 \%$ de uma família botânica.

Na cidade de Porto Alegre, segundo Puente et al.,(2001), na medida do possível, não são plantadas espécies que já estejam com freqüência superior à 15\%, há menos que se trate de grandes conjuntos ou que tenham valor histórico.

A análise dos instrumentos mostrou os resultados descritos a seguir:

Pergunta 1 - Qual o nome da árvore em frente a sua residência?

Embora o número de moradores que conhecem a espécie plantada em frente à sua residência seja bem expressivo, 48\% dos entrevistados, a maioria não sabe de que espécie se trata, preferindo não arriscar nenhum nome, o que me comprovado pela alta porcentagem de entrevistados que enquadraram-se no item não sabe. (Figura 1).

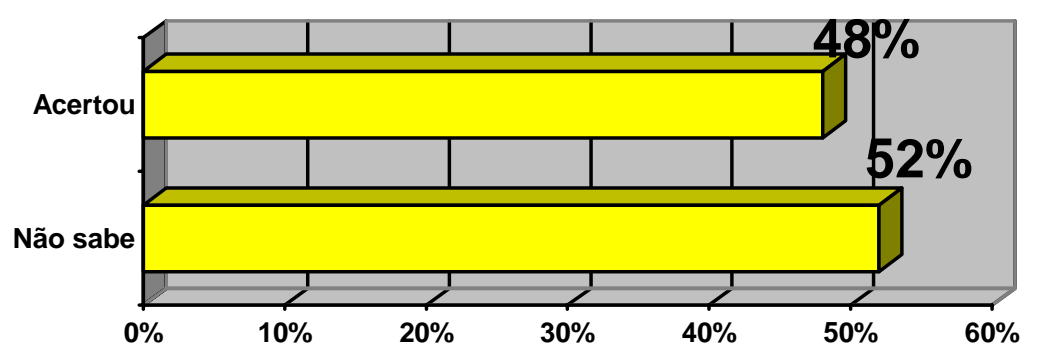

FIGURA 1 - Resultado da identificação pelos moradores da(s) espécie(s) plantadas em frente às suas residências, nos três parques residenciais no Bairro Camobi, Santa Maria (RS) realizada pelos proprietários.

Cada ser humano percebe e reage diferentemente sobre o ambiente, reconhecendo que a arborização, além de suas funções básicas ambientais, funciona no cotidiano da população como elemento referencial marcante. Foi constatado que as espécies arbóreas destacam-se como importantes sob os aspectos cultural, estético e paisagísticos de referência local; levantam questões sobre o comportamento humano e os valores culturais que norteiam as atitudes. A cultura reflete essa influência do ambiente sobre cada indivíduo colocando-o como resultante de um processo perceptivo (Oliveira, 2005).

Pergunta 2.1 - Quem plantou o exemplar?

A prática da arborização nestes loteamentos tem sido feita de forma espontânea pelos munícipes, seja o atual ou antigo proprietário, pois 91,66\% das árvores plantadas foram realizadas 
desta forma, como se observa na Figura 2. O Poder Público foi responsável por apenas 4,17\%, denotando a falta do exercício de uma prática que afeta a sua responsabilidade.

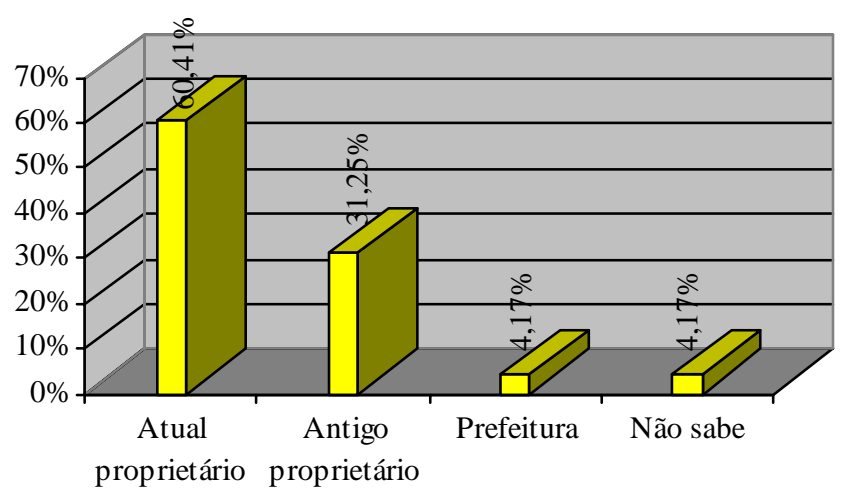

FIGURA 2 - Responsáveis pelos plantios ao longo das vias de três parques residenciais no Bairro Camobi, Santa Maria (RS).

Em termos de Direito Urbanístico o art. 22 da Lei 6766/79- Lei do Parcelamento do Solo impõe para o registro de parcelamento a constituição e integração ao domínio público das vias de comunicação, praças e os espaços livres. Nestes últimos estão incluídas as áreas verdes. Pelo art. 23 da citada lei, os espaços livres - entre eles as áreas verdes, como dito - passam a integrar o domínio público do município e em muitos deles as leis de parcelamento do solo determinam que nos projetos de loteamento sejam destinadas percentuais do imóvel a áreas verdes. Assim, os espaços verdes ou áreas verdes, incluindo-se aí, as árvores que ladeiam as vias públicas, fruto da arborização urbana, também por serem seus acessórios que devem acompanhar o principal, são bens públicos de uso comum do povo, nos termos do art. 66 do Código Civil, estando à disposição da coletividade, o que implica na obrigação municipal de gestão, devendo o poder público local cuidar destes bens públicos de forma a manter a sua condição de utilização.

O setor ambiental-conservacionista da administração municipal necessita, obrigatoriamente, ter forte ação técnico-política junto ao setor de planejamento municipal, notadamente no que se refere ao zoneamento de uso do solo e sistema viário, como forma de melhor viabilizar a arborização (Milano e Dalcin, 2000).

Pergunta 2.2 Porque escolheu esta espécie?

Os percentuais apresentados pela Figura 3 demonstram, exatamente, que os juízos de valor próprios são que efetivamente predominam no momento da escolha da espécie a ser plantada em frente à residência, pois 58,54\% afirmaram que escolheram por que gostam daquela árvore.

Em Rio Claro (SP), em pesquisa de opinião pública, moradores de vários bairros, em sua maioria também se expressam através do "gostar de árvores" quando são inquiridos sobre a 
espécie que compõem a arborização presente em frente a sua casa ou rua (Souza e Foresti, 2000).

A falta de uma política ambiental do Poder Público, para este setor, agravada ainda mais, pela falta de orientação técnica sobre qual espécie é mais adequada, fazem com que ocorram plantios espontâneos por parte dos munícipes acarretando em uma arborização extremamente heterogênea como pode ser observada na Tabela 1.

Ocorre ainda, embora com pequeno percentual (2,44\%), o processo de doações através de amigos ou ainda campanhas de empresas que no afã de tornar "verde" esta, ou outra cidade, criaram campanhas de doações de mudas de espécies ornamentais, porém sem orientar sobre as questões técnicas que envolvem o plantio e porte da mesma quando adulta (Figura 3).

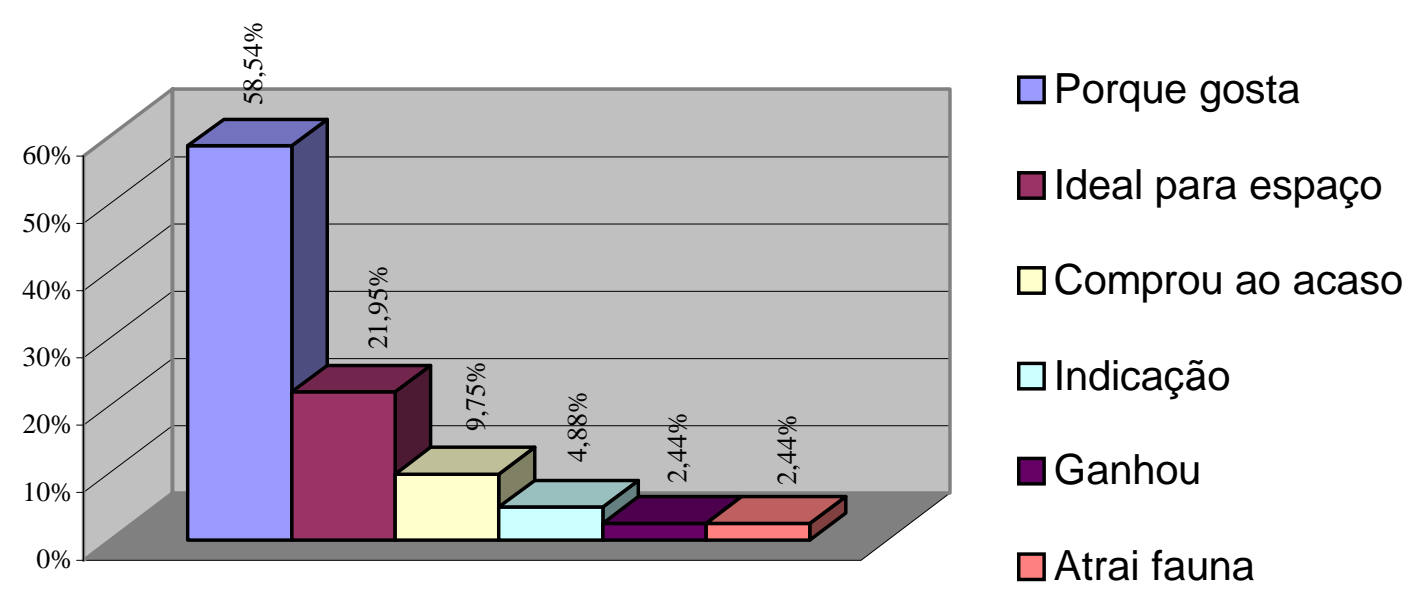

FIGURA 3 - Motivos apresentados pelos moradores para a presença das espécies vegetais na arborização de três parques residenciais no Bairro Camobi, Santa Maria (RS).

$\mathrm{Na}$ escolha da espécie para arborizar, o gosto pessoal deve ser sempre colocado em segundo plano, em relação às necessidades da coletividade. Características botânicas da espécie vegetal, arquitetônicas e paisagísticas do local a ser arborizado, devem nortear a escolha da planta. O bom senso e o gosto pessoal não são critérios para escolha de espécies arbóreas (Santana e Santos, 1999).

O plantio voluntário pode levar ao excesso de espécies, gerando composições pouco estéticas. E, em alguns planos de arborização, a escassez de espécies pode sugerir monotonia, induzir de forma imediata intervenções para a adequação e ser comprometida, mais facilmente, por problemas sanitários (Santos e Teixeira, 2001)

Pergunta 3 - Tem informações sobre a espécie, tais como porte, folhas, frutos, raízes, etc...?

O conhecimento empírico fica claro em função de informações obtidas através de visualização da planta escolhida ou de outras pessoas que repassam às primeiras características 
Percepção ambiental dos moradores...

genéricas sobre a planta. A partir desta premissa, a maioria, 58,33\% respondeu que conhecem as características das plantas como está apresentando a Figura 4.

Pesquisa realizada em vários bairros da cidade de São Paulo buscando relacionar a importância das árvores para os moradores, enquanto cidadão e para o lugar em questão, demonstrou um grande desconhecimento da maioria da população sobre as características das espécies arbóreas (Leme, 2000)

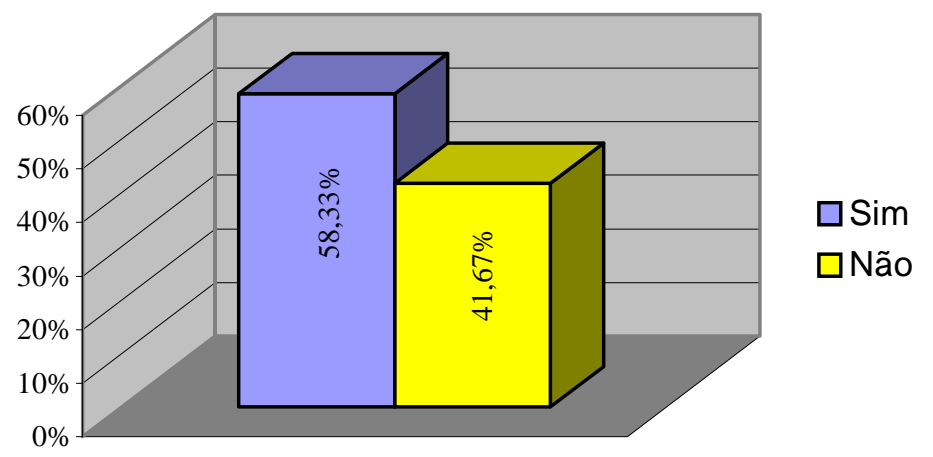

FIGURA 4 - Resposta dos moradores quanto a ter informações sobre as espécies plantadas ao longo das vias de três parques residenciais no Bairro Camobi, Santa Maria (RS).

Pergunta 4 - Considera o espaço deixado na calçada suficiente para o desenvolvimento da planta?

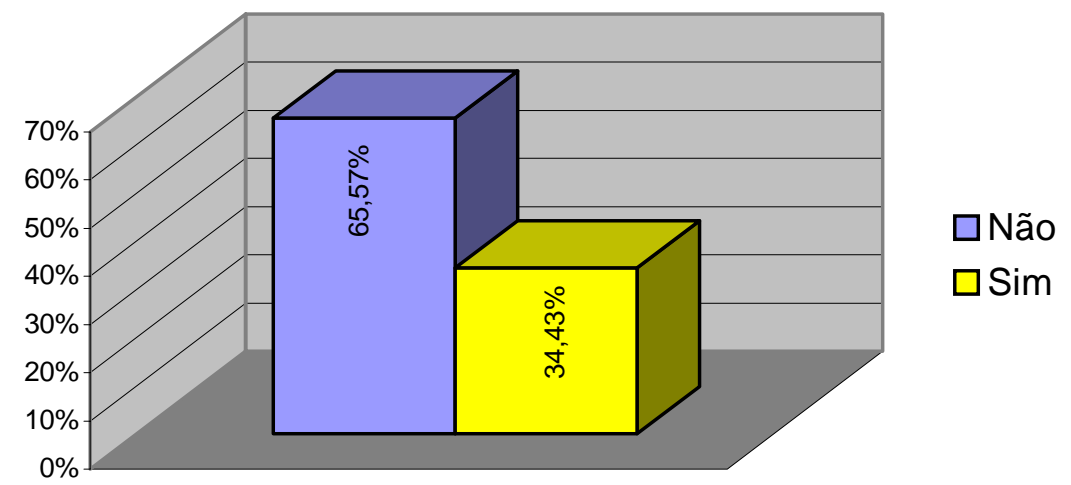

FIGURA 5 - Presença de áreas livres junto aos exemplares que constituem a arborização das vias de três parques residenciais no Bairro Camobi, Santa Maria (RS).

Os percentuais que a Figura 5 oportuniza, deixa claro que ocorre uma conscientização sobre os problemas relacionados à área livre para as espécies vegetais se desenvolverem visto que $65,57 \%$ dos entrevistados consideram que o espaço não é suficiente. Esta situação é fruto, principalmente, da falta de planejamento no momento da construção da calçada somando a falta de informações sobre a silvicultura da espécie e do processo de arborização de ruas.

Esta afirmativa é corroborada pela Figura 6, onde se observa elevado percentual de calçadas sem área livre para a árvore se desenvolver, ou seja, todo o colo da planta está cercado PPop 
ou espaços muito exíguos, de área livre, não compatibilizaram com o crescimento das espécies vegetais apresentadas no censo realizado. Deve-se salientar também uma elevada variedade de metragens apresentadas pelas áreas livres denotando a falta de critério técnico para dimensionálas dentro de padrões técnicos específicos.

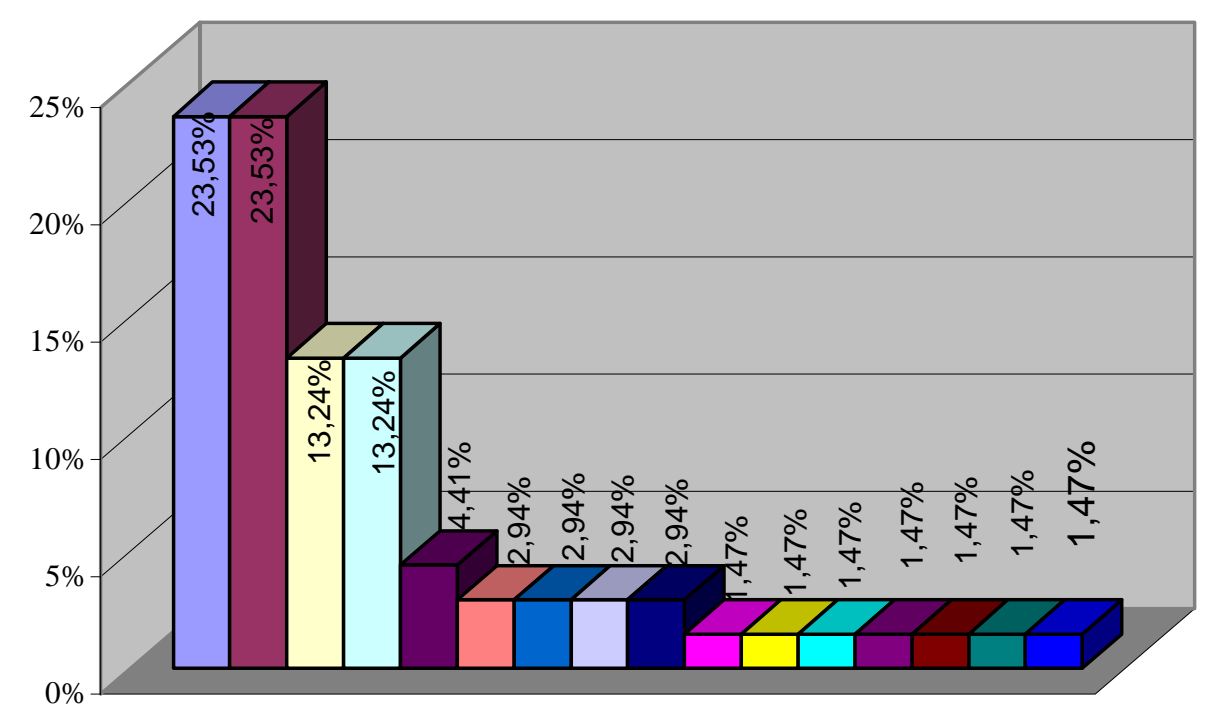

$\square$ Sem área livre
$\square 0,40 \times 0,40$
$\square 0,30 \times 0,30$
$\square 0,50 \times 0,50$
$\square 0,50 \times 8,0$
$\square 0,15 \times 0,15$
$\square 0,45 \times 10$
$\square 0,5 \times 10$
$\square 0,5 \times 5,0$
$\square 0,20 \times 0,20$
$\square 0,30 \times 8,0$
$\square 1,0 \times 0,9$
$\square 0,5 \times 6,0$
$\square 0,5 \times 4,0$
$\square 1,0 \times 4,0$
$\square 0,9 \times 0,9$

FIGURA 6 - Valores relativos à área livre na arborização das vias de três parques residenciais no Bairro Camobi, Santa Maria (RS).

Meneghetti (2005) apresenta uma situação semelhante quanto aos bairros da orla marítima da cidade de Santos onde, por meio de uma pesquisa, determinando-se como área livre adequada a que possui dimensões de $0,40 \times 0,40 \mathrm{~m}$, obteve do total amostrado $32,7 \%$ com área livre suficiente para o desenvolvimento das espécies vegetais, enquanto a maioria, 51\%, foi considerada pequena (menor que a área livre adequada) e 16,4\% estava totalmente cimentada ou ocupada por raízes.

Pergunta 5.1 O exemplar já foi podado?

A prática de "podar" árvores está inserida na cultura popular, principalmente, na região sul onde motivos como "meses sem erre", "sujeira", "tradição" e outros fazem com que os moradores se lancem a esta prática silvicultural que na maioria das vezes é praticada de forma totalmente inadequada. 


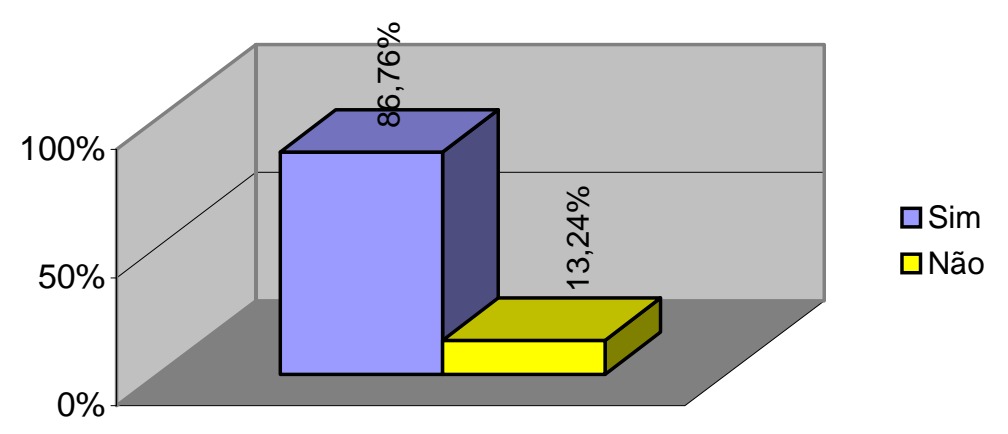

FIGURA 7 - Respostas atribuídas pelos moradores se o exemplar havia sido podado ou não ao longo das vias de três parques residenciais no Bairro Camobi, Santa Maria (RS), quanto a prática da poda.

Os altos valores afirmativos quando questionados se a espécie já havia sido podada, observados na Figura 7, denotam exatamente uma situação que não é restrita apenas a estes loteamentos ou bairro, mas a um complexo sistema cultural hereditário observado em muitos municípios brasileiros embora ocorram leis municipais regendo este assunto.

Silva (2005) estudando a cidade de Americana-SP constatou que 52,60\% das árvores inventariadas já tinham sofrido intervenções de diversos tipos de podas.

Lima (1992) ao analisar a situação da arborização viária de uma área do município de Piracicaba/SP obteve como um dos resultados a ocorrência de 69,9\% das árvores podadas.

Pergunta 5.2 Quem praticou a poda?

Velasco (2003) cita o artigo 65 do Código Civil onde consta que as ruas são bens públicos e as árvores nelas plantadas pertencem ao município. Desta forma, a poda das árvores é de responsabilidade destes, os quais devem zelar pela manutenção dos bens públicos. Assim sendo as Prefeituras Municipais são responsáveis pela poda das árvores, embora as concessionárias de energia elétrica possam executá-las quando houver riscos para as pessoas, para as instalações e/ou interrupções de energia, causadas por árvores próximas a rede.

Magalhães et al (1990) enfatizam que tais podas emergenciais só serão feitas quando não houver providências, em tempo hábil, por parte das Prefeituras Municipais. 


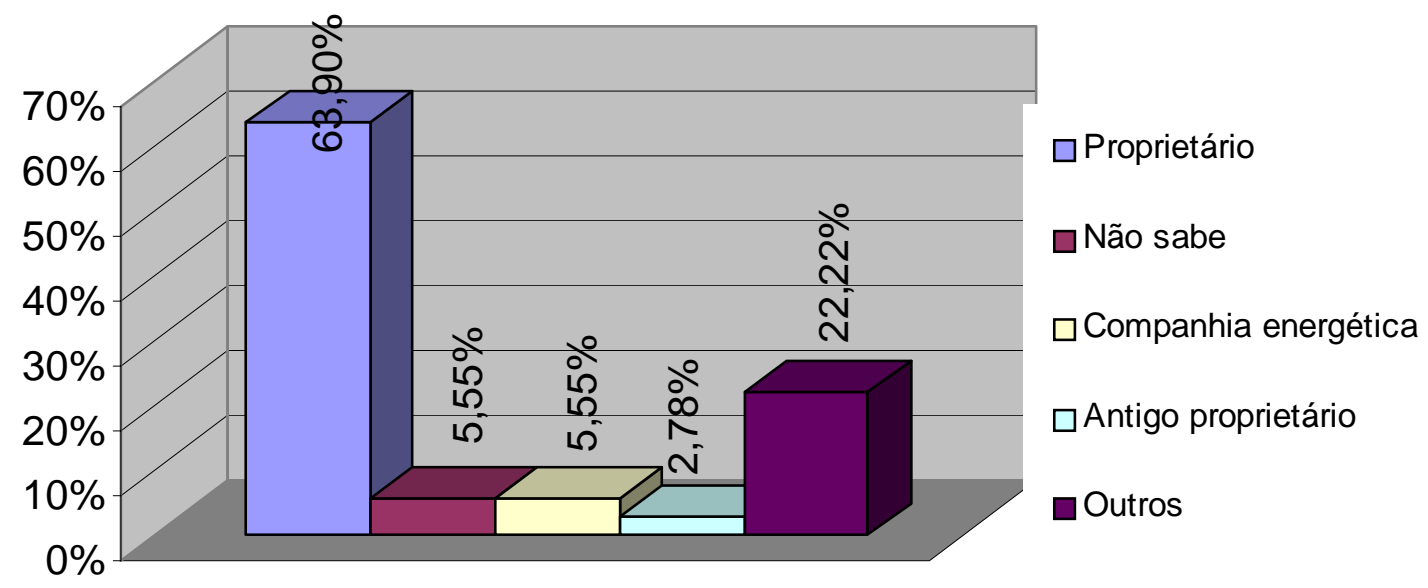

FIGURA 8 - Respostas ao questionamento sobre quem podou os exemplares que constituem a arborização de três parques residenciais no Bairro Camobi, Santa Maria (RS).

Embora seja atribuição do Poder Público a manutenção do verde urbano de uma cidade, ainda ocorre uma transferência de atribuições para o munícipe, não oficialmente, mas pela ausência da ação efetiva por parte do executor legal. Com isto o percentual de podas realizadas pelos munícipes entrevistados, 63,90\% segundo a Figura 8, é grande assim como os futuros danos às arvores posteriores à poda também o serão.

O problema do manejo em arborização de ruas é bastante complexo e a insatisfação faz com que o munícipe realize esta atividade ou pague para executá-la. Neste sentido foi desenvolvida uma pesquisa de opinião pública como parte de um trabalho no bairro de Vila Isabel, Rio de Janeiro e em relação ao manejo das árvores, 63\% dos entrevistados avaliam negativamente a atuação da Fundação Parques e Jardins, órgão público responsável por este serviço (Ribeiro et al., 2001).

Pergunta 6 - Qual a função que o exemplar cumpre no local?

O homem urbano no afã de reproduzir uma paisagem que outrora o ligava ao ambiente natural, busca reproduzir no seu meio um pequeno elo de ligação através do "verde" das espécies vegetais. Neste sentido o conceito de "belo" é o primeiro a ser citado no conjunto dos itens de escolha das espécies vegetais. Esta beleza deve ser traduzida principalmente em um florescimento expressivo e forma da espécie vegetal. Desta forma 48,05\% dos entrevistados afirmaram ser este atributo o que sintetiza a maior função nas vias dos loteamentos (Figura 9).

Para 52.49\% dos moradores em Ilha Solteira-SP, a atribuição da importância da arborização urbana recai diretamente em seu efeito de ornamentação (Nunes Júnior, 2000).

Segundo Godoy (1995), em pesquisa realizada na cidade de Pirassununga, 62.19\% da população credita esta mesma função a arborização urbana. 
Percepção ambiental dos moradores...

Outro fator importante é a sombra, pois é um elemento ligado diretamente ao conforto ambiental do morador, principalmente no sentido de reduzir as amplitudes térmicas que ocorrem no período primavera-verão, tendo sido observado como uma função importante por $41,55 \%$ dos moradores questionados (Figura 9).

A vegetação tem influência direta na melhoria da qualidade climática para o conforto dos seres vivos. Isto se dá porque a vegetação tem um papel significativo no estabelecimento de microclimas. Um microclima se caracteriza por definir em uma área restrita, características climáticas diferentes do clima que o circunda, estas características diferentes são produto por um lado da configuração espacial do local, que proporciona condições para o estabelecimento deste microclima, por outro lado, depende dos elementos de clima que interagem no local, propiciando com seus condicionantes características diferentes do entorno (César,2003).

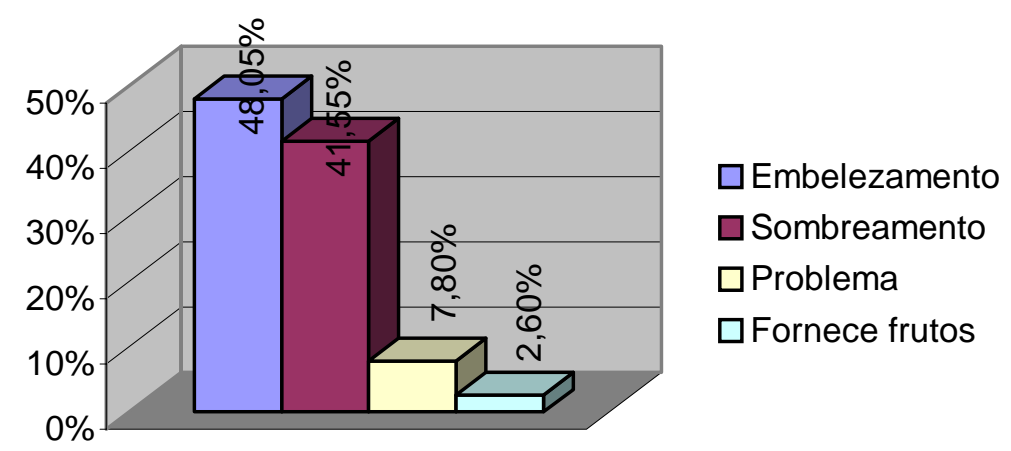

FIGURA 9 - Função atribuída aos exemplares que compõem a arborização de vias de três parques residenciais no Bairro Camobi, Santa Maria (RS).

Segundo Izard e Guyot (1980), os efeitos produzidos pela massa foliar da copa das árvores na área por elas sombreadas e protegidas, guarda muita relação com a diminuição da temperatura no local: "Cria uma espécie de "céu" e sua temperatura radiante é mais elevada que a abóbada celeste, o que permite uma diminuição da emissão de radiação infravermelha da superfície terrestre". Outro processo pelo qual a vegetação participa da criação de um clima melhor, é o processo da fotossíntese. Onde a liberação de gases através da respiração foliar, restitui ao ar gotículas de vapor d'água, que entre outras coisas auxilia a umidificação do ar.

Notadamente o porte, a forma, a cor e a textura estão presentes nos troncos e nas copas. Entre as características formais das copas, a que mais especificamente tem interesse para este estudo é a densidade foliar. Esta característica é importante porque não diz respeito aos aspectos relacionados somente às árvores, mas as possibilidades que podem ser proporcionadas a partir do relacionamento com o entorno e também da qualidade que o espaço tem a oferecer, tais como, a incidência de luz, a exposição do solo às intempéries, as barreiras visuais com o entorno, além da própria configuração formal das árvores. A categoria destas coberturas se relaciona àquelas espécies vegetais que apresentam uma densa "massa foliar", especialmente nas partes mais periféricas e superficiais da copa e que proporcionam uma grande proteção dos raios solares, 
deixando passar no máximo até 30\% destes. Há um grande fechamento da cobertura que constitui com clareza "um teto"(César,2003).

Malavasi e Malavasi (2001) ao abordarem a população de Candido Rondon-PR quanto à percepção trabalharam com a idéia de vantagem e desvantagem da arborização urbana e obtiveram uma resposta afirmativa de $92 \%$ dos entrevistados que apontaram o sombreamento com $65 \%$ e a redução de calor com $23 \%$ como as vantagens mais efetivas, seguidas pela presença de flores e pela redução dos ruídos com $4 \%$ cada. Por outro lado, as desvantagens mais freqüentemente citadas por $8 \%$ foram a sujeira das ruas e calçadas com $56 \%$ e a sujeira provocada pos pássaros com 14\%, seguidas pela redução na iluminação pública e problemas com a rede elétrica ambas com $8 \%$ cada.

Pergunta 7.1 Você manteria este exemplar em frente a sua casa ou substituiria?

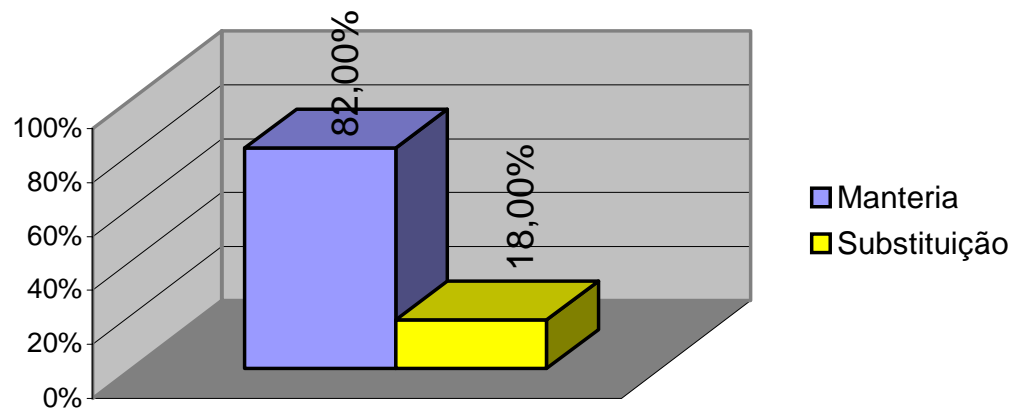

FIGURA 10 - Posição dos moradores de três parques residenciais no Bairro Camobi, Santa Maria (RS) quanto a manutenção dos exemplares plantados frente à sua residência.

A maioria dos entrevistados (82\%) por desconhecer as características das espécies manteria as já plantadas conforme a Figura 10. A falta de informações técnicas sobre as espécies vegetais reflete-se exatamente na alternativa de substituição.

Enquanto que a falta de informações e juízos de valores próprios fazem com que os moradores não optem por substituir uma situação inversa é observada na cidade de Rio Gallegos, província de Santa Cruz, Argentina, onde foi desenvolvida uma pesquisa na área de arborização de ruas, com um inventário e pesquisa de opinião pública em $1,20 \%$ da população. Dentre as respostas obtidas está a grande demanda da população por ter novas espécies vegetais em frente às suas casas (Dias et al, 2001).

Pergunta 7.2 Que espécie colocaria?

Quando questionado sobre a possibilidade de substituição, a maioria, 66,67\% não saberiam por qual espécie e quando citaram, apenas reproduziram modelos já utilizados com muita freqüência, como o Ligustro, que estão usando, como o Ingá, e outro totalmente incompatível com a arborização de acompanhamento viário que é a palmeira Areca-bambu (Figura 10). 


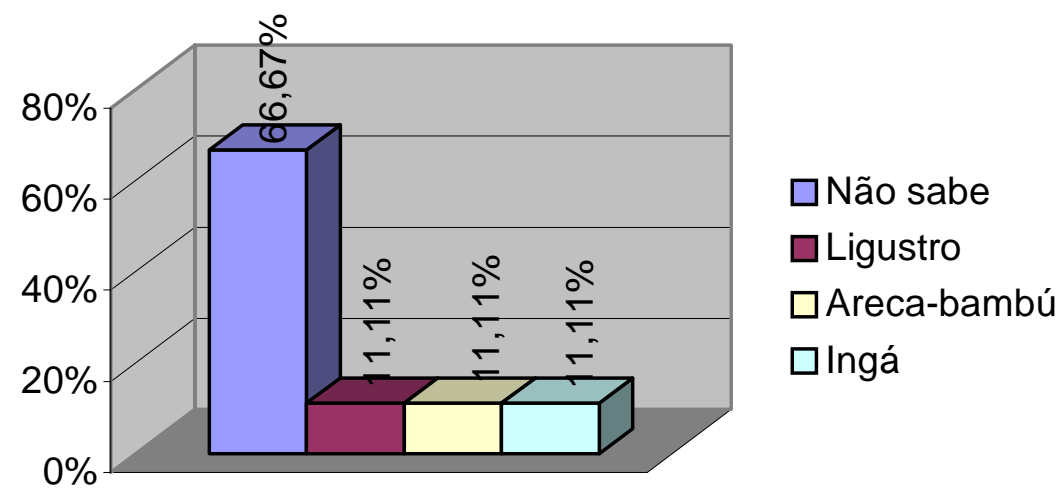

FIGURA 11 - Indicação dos moradores quanto às espécies vegetais a serem utilizadas para substituir a arborização existente em frente à sua residência em três parques residenciais no Bairro Camobi, Santa Maria (RS).

A tendência à urbanização apresenta-se como um desafio para os técnicos administrativos, pois as aglomerações humanas e suas atividades provocam uma ruptura do funcionamento do ambiente natural nela estabelecido, compondo um importante indicador biológico da qualidade ambiental destes centros. A diversidade da vegetação urbana pode apresentar-se como um destes indicadores, onde a homogeneidade das espécies utilizadas pode representar ambientes altamente alterados, seja por questões culturais (preferência por plantas que não são nativas) ou pelo fato da vegetação nativa não ter mais condições de estabelecer-se naturalmente (Cavalheiro, 1995).

Pergunta 8 - Na sua opinião quem deveria ser responsável pelo plantio e manutenção das calçadas?

O entrevistado manifestou-se, em sua maioria (67,30\%), como sendo responsável pois como não percebe o Poder Público executando esta atividade então apropriou-se da mesma, como pode-se verificar através da Figura 12.

A questão está intimamente ligada ao fato do meio ambiente urbano ter sido considerado pela administração pública como fator secundário frente às necessidades de constantes melhorias no desempenho econômico regional. Dentro desta perspectiva, os benefícios decorrentes de um ambiente saudável nem sempre estão presentes nas ações do planejamento público destas áreas. No entanto seus efeitos, se bem aproveitados, poderiam ter papel fundamental na qualidade de vida da população (Nunes Jr. e Monteiro, 2001). 


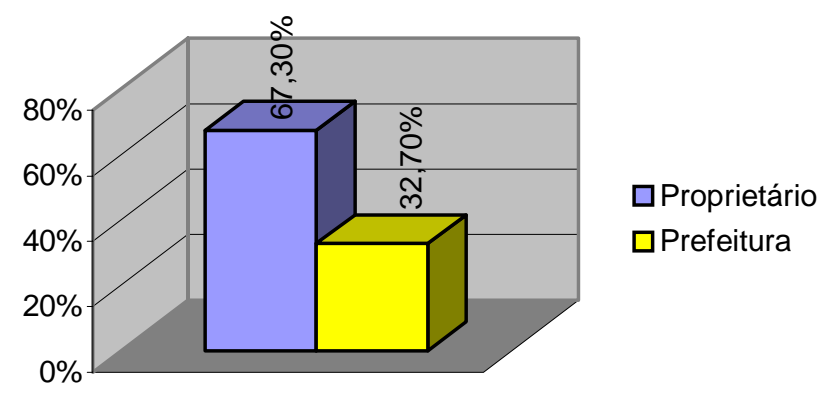

FIGURA 12 - Posição dos moradores de três parques residenciais no Bairro Camobi, Santa Maria (RS) quanto a responsabilidade pela implantação e manutenção das arborizações viárias.

As prefeituras municipais devem executar e manter a arborização urbana, pois a competência para tal reside nos planos diretores e leis do uso do solo dos municípios ou regiões metropolitanas os quais devem observar os princípios e limites previstos no art. $2^{\circ}$, parágrafo único do Código Florestal que foi acrescentado pela lei 7.803/89 (Silva, 1995).

O meio ambiente sadio é um direito de todo cidadão como está citado no art.225 da Constituição Federal. Aliás, por se tratar de uma atividade de ordem pública imprescindível ao bem estar da população, nos termos dos arts.30,VIII, 183 e 183 da Constituição Federal e do Estatuto da Cidade (Lei 10.257/01), cabe ao Poder Público municipal em sua política de desenvolvimento urbano, entre outras atribuições, criar, preservar e proteger as áreas verdes da cidade, mediante leis específicas, bem como regulamentar o sistema de arborização. Disciplinar a poda das árvores e criar viveiros municipais de mudas está entre as providências específicas neste sentido, sem contar na importância de normas sobre o tema no plano diretor, por exemplo.

Preocupação com manutenção das árvores para evitar acidentes por queda, poda tecnicamente correta para evitar danificar as árvores e a fiação elétrica, manutenção de canteiros para garantir a limpeza e a presença de mais flores na arborização urbana são desejos manifestados por parte da população e estão também relacionados com a qualidade de vida da cidade (Oliveira, 2005).

O planejamento da infra-estrutura verde inclui a identificação dos elementos e suas funções; as necessidades e os serviços desejados; o mapeamento e o monitoramento adequados; o levantamento dos custos e benefícios; e o planejamento estratégico dos aprimoramentos do capital natural, em fases se necessário (Wolf, 2006).

\section{CONCLUSÕES}

O estudo desenvolvido nas onze vias que compõem três Parques Residenciais, no Bairro Camobi, na cidade de Santa Maria (RS), e a análise de um instrumento aplicado junto as residências, demonstraram que ocorre um processo de arborização voluntária o que se reflete em 
Percepção ambiental dos moradores...

plantios sem critérios técnicos, onde a escolha, condução e manejo das espécies fica sujeita aos juízos de valores dos moradores demonstrando com isso a omissão do Poder Público neste tema.

A falta de uma política pública específica para este setor ao longo das Administrações que se sucederam na cidade de Santa Maria-RS, tem se refletido em uma arborização totalmente heterogênea, sem planejamento para implantação e manutenção, assim como refletem a continuidade de modelos apresentados em cidades mais antigas inclusive na escolha das espécies.

Isto caracteriza a ação do privado frente a sua necessidade premente como cidadão e a inoperância do público para resolver um problema que é basicamente de prestar serviço relacionado a qualidade de vida para os seus munícipes.

\section{REFERÊNCIAS BIBLIOGRAFICAS}

CASTELLO, L. Psicologia ambiental e política ambiental: estratégias para a construção do futuro. Psicologia USP, 16(1/2), p. 223-236, 2006.

CAVALHEIRO F. Urbanização e alterações ambientais. In Análise ambiental: uma visão multidisciplinar. 2 ed. São Paulo: Editora da Universidade Estadual Paulista. 1995. 114-25p

CESAR, L.P. de M. Os espaços livres, a escolha e distribuição da vegetação e algumas considerações sobre a composição do espaço urbano. Correio Brasileense, Brasília, 04 de março de 2003. Caderno Direito e Justiça, p.2-3.

DIAZ, B.; MAZZONI, A.; CLAPS, L.; MONELOS, L.. Encuesta forestal voluntária. Rio Gallegos: Municipalidad de Rio Gallegos. 2001. 18 p.

GODOY A. L. P. Cidade e Meio Ambiente: O Planejamento da Arborização de Pirassununga-SP. São Paulo. UNESP - Instituto de Geociências. (Dissertação) Disponível em <http://tender.igce.unesp.br/igce/geologia/gma-m40.htm > acessado em 10/06/2005.

GREY, G.W. e DENEKE, F. Urban forestry. New York: John Wiley, 1978.

IBGE. Censo 2000. Disponível em: <http://www.ibge.gov.br>. Acesso em: 12 abr. 2007.

IZARD, J. L. e GUYOT, Q. Arquitectura Bioclimática. Barcelona: Ed. G. Gilli. 1980.

LASCHI, D.L.; NUNES, F.C.; ESVICERO, L.; SOUZA, H.G.; GARCIA, P.A.; SILVA, R.R. Inventário da arborização e proposta de re-arborização do Bairro Jardim Paraíso, na cidade de Botucatu/SP. 
In: CONGRESSO BRASILEIRO DE ARBORIZAÇÃO URBANA, 7, 2003, Belém/PA. Anais... Belém/PA: UFRA, 2003, vol. 1.

LIMA, A.M.L.P. Piracicaba/SP: Análise da arborização viária na área central e em seu entorno. 1993. 238 f. Tese (Doutorado) - Escola Superior de Agronomia "Luiz de Queiroz", USP, Piracicaba,1993.

LIMA, C. B. e TOME, M. V. D. F. Levantamento Etnobotânico da Arborização Urbana de Bandeirantes - PR. In: CONGRESSO E EXPOSIÇÃO INTERNACIONAL SOBRE FLORESTAS, 5., Bio 5017, 1999, Curitiba - PR. Anais... Paraná: Sociedade Brasileira para a Valorização do Meio Ambiente, CD ROM.

LEME, I. S. A percepção da paisagem através da arborização. In: CONGRESSO BRASILEIRO DE ARBORIZAÇÃO URBANA, 7, 2000, 2003, Belém/PA. Anais... Belém/PA: UFRA, 2003, vol. 1.

LOBODA, C. R.; DE ANGELIS, B.L.D.; DE ANGELIS NETO, G.; SILVA, E. S. da. Avaliação das áreas verdes em espaços públicos no município de Guarapuava-PR. Ambiência. v.1. n. 1. p. 141155. 2005.

MAGALHÃES, I.M.de; NAKAZATO, A.S.; RODRIGUES, F.M. Coexistência dos sistemas elétricos de distribuição e arborização. In: ENCONTRO NACIONAL DE ARBORIZAÇÃO URBANA, 3., 1990, Curitiba. Anais... Curitiba: FUPEF, 1990. p. 228-235.

MALAVASI, U.C. e MALAVASI, M. de M. Avaliação da arborização urbana pelos residentes estudo de caso em MAL. Cândido Rondon, PR. Ciência Florestal, Santa Maria, v.11, n.1, p.189193, 2001.

MENEGHETTI, G. I. P. Estudo de dois métodos de amostragem para inventário da arborização de ruas dos bairros da orla marítima do município de Santos - SP. Piracicaba, 2005. 100 p. Dissertação (Mestrado) - Escola Superior de Agricultura "Luiz de Queiroz", Universidade de São Paulo.

MILANO, M.S. e DALCIN, E. Arborização de vias públicas. Rio de Janeiro: Light, 2000.

MOLL, G. Improving the health of the urban forest. American Forest, v.93, n.11/12, p. 61-64, nov/dec. 1987. 
Percepção ambiental dos moradores...

NUNES JR. M.S. e MONTEIRO, R.C. Proposta metodológica para análise ambiental: o caso da arborização urbana de llha Solteira-SP. In: ENCONTRO NACIONAL DE ARBORIZAÇÃO URBANA, 4, 2001, Brasília. Anais... Brasília: SBAU, 2001, 1 CD-ROM.

NUNES JÚNIOR, M. S. Análise da arborização urbana de Ilha Solteira-SP. Ilha Solteira. In_ REUNIÃO CIENTÍFICA. Anais... Ilha Solteira:Universidade Estadual Paulista - FE. 2000, 1 CDROM.

OLIVEIRA, E.Z. A percepção ambiental da arborização urbana dos usuários da avenida Afonso Pena entre as ruas Calógeras e Ceará da cidade de Campo Grande - MS. Campo Grande. 2005. 125 p. Dissertação (Mestrado), UNIDERP, 2005.

OKAMOTO, J. Percepção ambiental e comportamento. São Paulo: Plêiade, 1996

PUENTE, A.D.; PICCOLI, L.A.; SANCHOTENE, M.do C. Metodologia de atendimento a solicitações de plantio da comunidade. In: ENCONTRO NACIONAL DE ARBORIZAÇÃO URBANA, 4, 2001, Brasília. Anais... Brasília: SBAU, 2001, 1 CD-ROM.

RIBEIRO, H.M; PIRES, B.B.M.; SANTOS, L.F.U. dos; SIMÕES, L.O. de L.; COSTA, A.J.S.T. da. Arborização em espaço urbano uma proposta metodológica no bairro de Vila Isabel, Rio de Janeiro, RJ. In: ENCONTRO NACIONAL DE ARBORIZAÇÃO URBANA, 4, 2001, Brasília. Anais... Brasília: SBAU, 2001, 1 CD-ROM.

RUSCHEL, D. e LEITE, S.L.de C. Arborização urbana em uma área da cidade de Lajeado, Rio Grande do Sul, Brasil. Caderno de Pesquisa Sér. Bio., Santa Cruz do Sul, v. 14, n. 1, p. 07-24, jan./jun. 2002.

SANTANA, J. R. F de e; SANTOS, G.M. de M. Arborização do Campus da UEFS: exemplo a ser seguido ou grande equívoco? Sitientibus, n.20, p.103-107. 1999.

SANTAMOUR JÚNIOR, F.S. Trees for urban planting: diversity uniformity, and common sense. In: METRIA CONFERENCE, 7., 1990, Lisle. Proceedings. Lisle: 2002. p.57-66.

SANTOS, N.R.Z. dos; TEIXEIRA, I.F. Arborização de Vias Públicas: Ambiente X Vegetação. Santa Cruz do Sul: Instituto Souza Cruz, 2001, 135 p. 
SILVA, L.F. da. Situação da arborização viária e proposta de espécies para os bairros Antônio Zanaga I e II, da cidade de Americana/SP. Piracicaba, 2005. 80 p. Dissertação (Mestrado) - Escola Superior de Agricultura "Luiz de Queiroz", Universidade de São Paulo.2005.

SOUZA, A. de S. e FORESTI, C. Avaliação do grau de conscientização da população de Rio Claro sobre a arborização urbana. In: VI SIMPÓSIO DO CURSO DE PÓS-GRADUAÇÃO EM CIÊNCIAS DA ENGENHARIA AMBIENTAL; VI, 2000; São Carlos, Anais...São Carlos: 2000, meio digital.

TRIGUEIRO, A. Meio ambiente no século 21: 21 especialistas falam da questão ambiental nas suas nas suas áreas de conhecimento. Rio de Janeiro: Sextante, 2003.

VELASCO. G. del N. Arborização viária $X$ sistemas de distribuição de energia elétrica: avaliação de custos, estudos das podas e levantamento de problemas fitotécnicos. Piracicaba, 2003. 94 p. Dissertação (Mestrado) - Escola Superior de Agricultura "Luiz de Queiroz", Universidade de São Paulo.2003.

ZUBE, E.H.; SELL, J.L.; TAYLOR, J. D. Landscape perception: research, application and theory. Landscape Planning, v.9, p. 1-3,1982.

WHYTE, A.V.T. La perception de l'environment: lignes directrices méthodologiques pour les études sur le terrain. Paris: UNESCO, 1978,134p.

WOLF, K.L. A economia e o valor público das florestas urbanas. Revista de Agricultura Urbana $n^{\circ}$ 13. File: $/ / / C \mid / D o c u m e n t s$ and Settings/Administrador/Escritorio/rediseño AU/pdfs/raup13/AU13economics.html (1 of 8)28/06/2006. 